\title{
Metacognitive awareness of TOEFL reading comprehension strategies
}

\author{
Dilyana D. Sungatullina ${ }^{1}$ Ekaterina O. Zalyaeva $^{1}$, and Yuliya N. Gorelova ${ }^{1 \mathrm{a}}$ \\ ${ }^{1}$ Kazan Federal University, 4, Butlerov st., Kazan, 420012, Russia
}

\begin{abstract}
The rising demand for exchange and mobility programs as well as double diploma opportunities with world leading universities highlights the importance of ESL proficiency. TOEFL iBT as a test of EAP is accepted by most of the HEI in various countries. The aim of the present study is to determine students' metacognitive awareness of global academic reading strategies, namely the use of context clues, within the framework of preparation for TOEFL reading section. The article establishes the connection between success in reading comprehension and the degree of students' metacognitive awareness. The authors concentrate on expository texts from TOEFL reading section as a testing material and provide detailed description of single context clues types and double context clues patterns typical for this text structure. The following study is concerned with comparison and interpretation of the results obtained in three focus groups of students, who have accomplished reading comprehension task from TOEFL iBT with and without learning to employ the context clues reading strategy
\end{abstract}

Keywords: Reading comprehension; metacognitive awareness; context clues; reading strategies, TOEFL.

\section{Introduction}

The rising demand for exchange and mobility programs as well as double diploma opportunities offered by many leading universities all over the world are becoming a growing concern and major challenge for education policymakers and researchers $[2,12]$ worldwide as it plays an increasingly important role in creating global educational environment [8, 13, 14 and 15] highlighting the importance of ESL (English as a Second Language) proficiency.

TOEFL iBT is the test of EAP (English for Academic Purposes) which is accepted by most of the higher educational establishments in various countries. It checks four basic

\footnotetext{
${ }^{a}$ Corresponding author: gorelovajuliya@gmail.com
} 
language skills: reading, listening, speaking and writing. Reading comprehension section being one of the largest and complex, includes a variety of text types as well as various task designs. Success in passing the reading subtest depends widely on the vocabulary size.

The problem is more acute due to the fact that texts presented in this section are deprived of subject-specific familiarity to avoid any advantageous environment for certain groups of test-takers. Furthermore, the majority of tasks are concentrated on the following purposes: reading to find information, reading for basic comprehension, reading to learn, reading to integrate information across multiple texts. Therefore, not the context knowledge itself, but the ability of test-takers to use the clues, which underlie any context is of a primary and detailed research. Although a number of issues in the field of global academic reading strategies metacognitive awareness have been analyzed and discussed $[4,5,6,16$, 19] much remains to be done in the field of context clues reading strategy implementation for TOEFL iBT preparation.

For carrying out our investigation it's of a great necessity to find the answer to the following question: Does students' metacognitive awareness of global academic reading strategies, namely the use of context clues, within the framework of preparation for TOEFL reading section, have an impact on efficiency of students' performance during the test?

\subsection{Theoretical review}

\subsubsection{Reading comprehension and metacognitive awareness}

Reading is a cognitive process in which readers interact with the text, forming hypothesis, predictions and using their background knowledge to construct the meaning [4, 19]. Reading involves numerous activities such as understanding and remembering ideas, identifying and selectively attending to important information, monitoring comprehension and learning, synthesizing information as well as critically evaluating a text in the academic context. Reading itself encompasses four crucial elements: the text, the reader, the interaction between the reader and the text, the mental state of the reader after the text interaction.

Reading comprehension in TOEFL is a process of the reader's cognitive interaction and motivational involvement with the testing material (text) under the goal of obtaining quantitative and qualitative results of proficiency in the English language [11], thus the better the reading comprehension skills, the higher are the chances of obtaining sufficient score at the exam.

Anderson (1984) suggests that second-language (L2) reading skills can be related to L2 proficiency. High overall competence in L2 leads to the improvement in reading ability. However, Carrell et al. state that thorough readers can complement for their inefficient language proficiency by increasing awareness of reading strategies and learning how to use these strategies. Successful comprehension does not occur automatically. Rather, successful comprehension depends on directed cognitive effort, referred to as metacognitive processing (Mehrdad et al., 2012). Carrell et al. consider metacognitive awareness as a critical element of proficient strategic reading. In this context metacognitive awareness is viewed as reader's awareness, monitoring and regulating of reading strategies [1].

\subsubsection{Types of reading strategies}

Nowadays, the identification of strategies used by test takers on tests of reading comprehension is of primary interest. In keeping with the understanding of reading as a problem-solving process, reading strategy analysis provides insights as to how readers 
interact with the text and how their choice of strategies influences their comprehension of the text. A focus on reading strategies helps researchers determine the extent to which readers genuinely understand the purpose of what they are reading, how they go about making sense of what they read, and what they do when they do not understand some aspect of the text.

Strategy use and efficacy are clearly influenced by the proficiency level of the reader. For example, Carrell and Grabe (2002) have underscored the importance of vocabulary knowledge in dealing with L2 text, as well as noting the difficulty non-native readers may have guessing words from context (a reading strategy), especially when the context is not very helpful. Furthermore, Skehan (1998) and others have warned that the task itself may pose true hurdles for the nonnative reader, and in fact, the length of a text and the nature of the questions asked about it on a test may have a real impact on the strategies that L2 readers use.

Planning and identifying strategies include planning how to read the passage, checking out any notable discourse features, remembering why the text is being read, checking for prior knowledge of the topic, reading through the whole text, reading portions selectively, looking for markers of meaning, and identifying portions of the text that are unclear. The strategies used during the reading process include monitoring ongoing understanding of the text, predicting what will come, rereading for clarification, and modifying comprehension based on new information (Andrew D. Cohen, Thomas A. Upton, 2006). In this research, we have developed an additional strategy which is not less helpful than those ones mentioned above. This strategy is aimed at using context clues to assess test takers' lexical, syntactic, and semantic abilities and their ability to understand important information presented in sentence-level propositions.

\subsubsection{Semantic and syntactic context clues strategy in TOEFL reading section}

The framework of TOEFL exam presupposes that any test-taker has a certain level of English language proficiency that will enable successful academic results achievement. In this light we are to investigate and consequently determine what is more important in the TOEFL preparation guidance: the students' exposure to the context clues strategy or the increase of their vocabulary knowledge.

\subsubsection{Word knowledge in reading comprehension}

Apparently the role of vocabulary cannot be underestimated in the process of reading comprehension. Furthermore, vocabulary acts as an integral part of a reading development process, [6].

Some researchers (Baumann et al., 2003; Beck \& McKeown, 1991) suggest that there are invisible bonds between vocabulary breadth and academic success. It is evident that limited vocabulary and word recognition will not give a student the opportunity to rely heavily upon the context and will consequently become a barrier to text content comprehension. To enlarge the vocabulary students might be exposed to the extensive reading (Heyens and Ahrens, 1998) as well as dictionary usage as a reference in understanding the content of a message (Robinson, 1998). However, all these practices are typical and absolutely necessary for students who are at the starting point of language investigation and show lack of independency in reading comprehension.

Nevertheless, TOEFL is an examination system initially designed to identify not the test-takers' vocabulary knowledge but those reading strategies selected for general comprehension, reading to learn and inferencing (Cohen \& Upton, 2006:18). Thus, we may 
suggest that vocabulary development is a constituent of any language learning process, though its volume cannot serve as an indicator of language proficiency.

\subsubsection{Context clues as an integral reading strategy in TOEFL}

Texts in TOEFL examination system are usually deprived of any graphic illustration whereas internal clues are not included into the current study since prefixes, suffixes, combining forms, word roots identification and understanding is an integral part of TOEFL test-taker's language proficiency. Thus, we define context clues as semantic and syntactic environment of a sentence in which the unknown word is enclosed into. Semantic features of context clues address to the test-taker's background as well as vocabulary knowledge whereas syntactic features apply to his sentence structure awareness, [11].

As can be expected lexical inferencing and understanding vocabulary in context is not the only reading sub-skill which is exposed to testing in TOEFL. In particular main idea comprehension, negative and positive feedback identification, specific information search, purpose definition, textual structure recognition , [11] along with the attitude determination are of a great value to be measured in TOEFL reading section. However, taking into consideration that the TOEFL reading section generally comprises 3 or 4 texts with a range of 36-44 questions depending on the TOEFL version (paper-based, internet-based), lexical inferencing sub-skills measurement tasks are abundant in number. For instance, "Cambridge Preparation for The TOEFL Test iBT" By J. Gear and R. Gear provides 7 sets of TOEFL practice tests with 3 types of texts (expository, argumentative and historical) in each reading section. The data gathered suggests that at least $30 \%$ of tasks proposed in each set have lexical inferencing and vocabulary understanding bias. Under these circumstances we may claim that a test-taker's exposure to the context clues reading strategy is of an exceptional importance since the testing procedure excludes any dictionary usage.

However, the effectiveness of context clues in reading comprehension is still a controversial topic. A series of studies claim that ESL students experience more difficulties in context clues strategy implementation in comparison with those students who are native speakers (Nagy, McClure \& Monsterrat, 1997). Nevertheless, granting that context clues instruction is characterized by explicit and distinct presentation technique, teacher feedback provision, clarity and adequacy of a task itself, students' encouragement and motivation together with students' presupposition, test-takers will be able to understand the word meaning and comprehend the main idea of the text. To take all possibilities into account, we are compelled to rule out the hypothesis that students' context clues reading strategy metacognitive awareness may guarantee a high level of test takers' academic achievement in TOEFL reading section.

\section{Method}

\subsection{Participants}

The recruitment test-takers process has come up with the Institute of Management, Economics and Finance, Kazan Federal University undergraduates, enrolled in an academic ESL program. As a result, 34 adult English language learners participated in this study. It should be noted, that the students varied in their English skill levels from low- intermediate to upper-intermediate ones. Finally, they were divided into three focus groups of 11-12 individuals, who have accomplished reading comprehension task from TOEFL iBT with and without learning to employ the appropriate reading strategies: the first group of 
students had no exposure to reading strategies; the second and the third groups received pre-test and post-test background knowledge accordingly.

The action research plan was explained to all of the students as well as the reason for conducting the research. It was also expounded that everyone would participate in the activity as part of the class curriculum, but that each student could decide to include or exempt his/her scores from the written research results. Before the data collection began, the classroom teacher chose the reading comprehension texts that would be used for the pre-test and post-test phases of the research. The pre-tests and post-tests were carefully correlated to match both the genre of the text and its reading level. The texts were not analyzed to determine if they fit well with the use of context clues, nor if they were altered anyway, since the goal was to figure out if context clues would help with independent reading occurring on standardized tests and in life outside the classroom.

As for pre-test and post-test groups of students a classroom teacher conducted a onehour lesson on reading strategies during a week. For instance, students were given a labeling system for determining what type of context clues are available, such as definitions within the sentence, opposites of a key word in the sentence, text in other parts of the story that give additional information, and situations that call upon students' prior knowledge. Each context clue had a practice sentence that allowed students to use a specific type of context clue to figure out the definition of the unknown word.

After five days of explicit instructions, modeling, and practicing of using reading strategies, the students started taking TOEFL iBT Reading section.

\subsection{Materials and methods}

Material for the research is taken from "Cambridge Preparation for The TOEFL Test iBT" by Jolene Gear and Robert Gear Book and covers a variety of reading texts used in the pretest and post-test study.

The prevailing research instruments employed by the authors are the experimental design and parametric design methods to make the most accurate and meaningful interpretation of the current study results.

The research paper also uses qualitative methods for description and interpretation of the various mistakes made by the test-takers when dealing with the reading passages; quantitative data analysis which is for calculating the percentage of successful, less successful and non-successful groups of test-takers. Descriptive statistics is applied as well for summarizing data to make them more comprehensible.

\section{Results and Discussion}

To investigate the significance of a test-taker's context clues reading strategy metacognitive awareness, first, three groups of students were exposed to the challenge of an argumentative text reading comprehension. Second, the effect of this strategy awareness was measured with the help of parametric design. The key factors of our experiment were: students' language proficiency level, the control of key variables (English classes exposure, context clues reading strategy instruction, additional reading assessment procedure), giving of a special treatment (context clues reading strategy pre- and post-instruction and additional reading assessment procedure) to different experimental groups, and comparison of three groups results.

As far as it is concerned with the hypothesis of this study the data yielded and depicted in Chart 1 and Chart 2 provide convincing evidence that context clues reading strategy awareness is beneficial for a test-taker. The 2nd Group of test-takers (exposed to the strategy) demonstrates higher level of performance with 8 test-takers clearing $50 \%$ barrier 
of the test, whereas in the 1 st group (without the exposure) only 3 test-takers gained relatively high scores in reading comprehension.

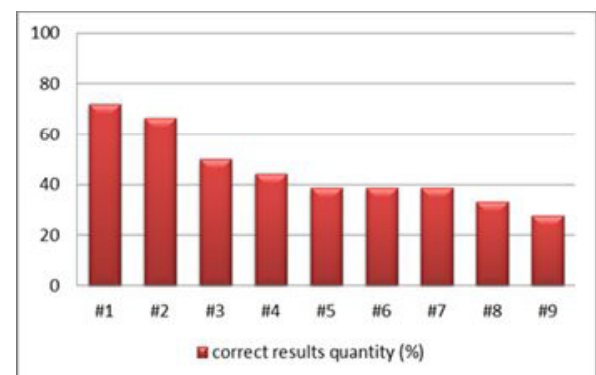

Chart 1. Test-takers not exposed to the context clues reading strategy

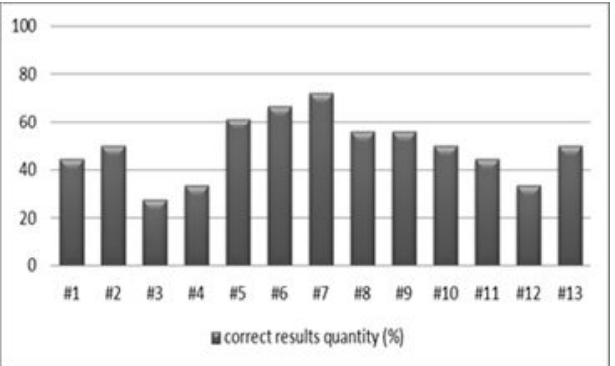

Chart 2. Test-takers exposed to the context clues reading strategy

The data obtained from the 3rd test-takers' Group (Chart 3) confirm the idea of a context clues strategy significance within the TOEFL reading section, since the enhancement in test-takers' results is indisputable. The test-takers' experience in context clues reading strategy implementation culminated in their scores improvement in lexical inferencing as well as general idea understanding and specific information search tasks.

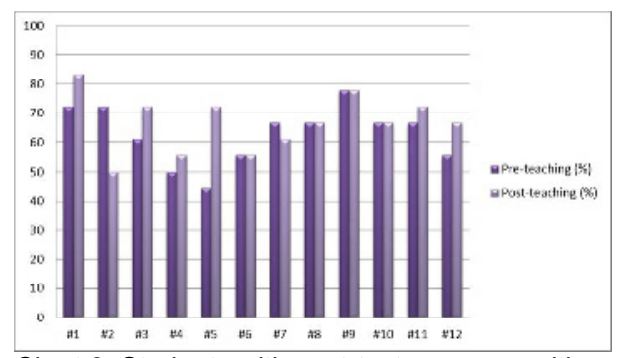

Chart 3. Students with post-test exposure with further repeated test procedure

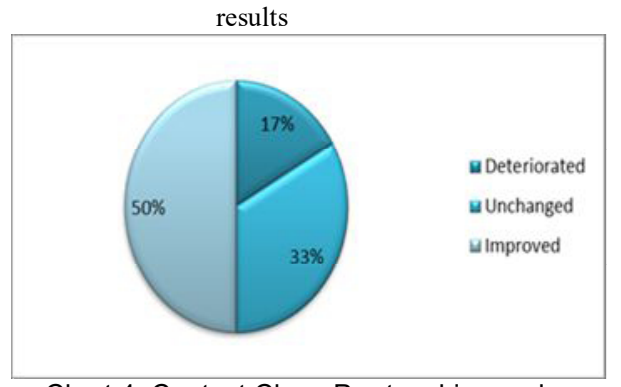

Chart 4. Context Clues Pre-teaching and Post-teaching

The outcome of our investigation represented in Chart 4 signifies the fact that only half of the 3rd test-takers' Group witnessed upward change in the results of their performance. Therefore, the enhancement of test-takers' success in TOEFL reading section is apparently governed by the time slot of their exposure to the instruction and training as well as the sequence of this tutorials' attendance, since the test-takers' with low showings were not fully involved to this strategy training.

With regard to our variables (variable one - qualitative characteristics of students' performance during the test, variable two - exposure to the context clues reading strategy), data in Chart 5 indicate that there is a significant difference in students' results. In other words more advanced testing results were revealed in the 3rd test-takers' Group whereas the 1st test-takers' Group registered inferior performance. 


\section{Conclusion}

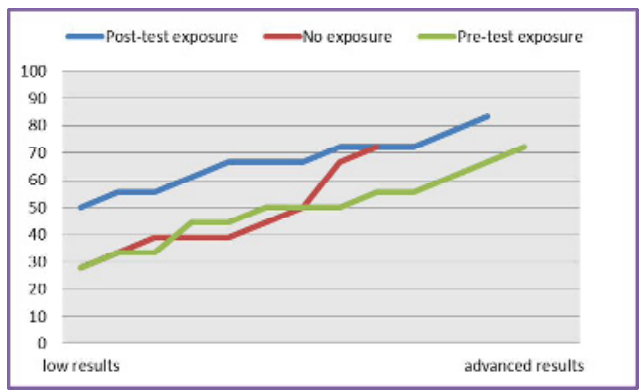

Chart 5. Context Clues exposure results factorial design

The findings of our research are quite convincing and, thus, the following conclusions can be drawn. Explicit instruction of context clues reading strategy benefited test-takers' unfamiliar words understanding as well as lexical inferencing. Students who were exposed to 2-weeks training and instruction were found to be more advanced and experienced in general understanding of the text and feedback identification in comparison with those who were not involved in the tutorial or were distinguished by meager attendance. Moreover, the former demonstrated lack of uncertainty in the interaction with unfamiliar textual material and transferred their skills to the new reading challenges. The present research confirms the concept of teaching and enlarging the vocabulary with the help of contextual clues surrounding new words and phrases, since they develop independency and confidence in a global understanding of the text, where a student doesn't find himself at a stalemate each time he encounters unfamiliar word. The results of our investigation may be taken into consideration in designing the steps for context clues reading strategy instruction or test tasks development along with the examination text selection.

\section{References}

1. Anderson, N. J., The role of metacognition in second/foreign language teaching and learning. ERIC Digest. Washington, DC: ERIC Clearinghouse on Languages and Linguistics, (2002).

2. Baklashova T., Manager's Professional Training in Russia: Syllabus and Technologies. Procedia - Social and Behavioral Sciences, 152, 1057-1061, (2014).

3. Brown, A., Bransford, J. D., Ferraraand, R., \& Campione, J.C., Learning, remembering and understanding. In J. H. Flavell \& E. M.Markman (Eds) Carmichael's Manual of Child Psychology, (1). New York: Wiley, (1983).

4. Carrell, P. L., Metacognitive Awareness and Second Language Reading. Modern Language Journal, 73, 121-134, (1989).

5. Carrell, P., Pharis, B., Liberto, J., Metacognitive strategy training for ESL reading. TESOL Quarterly, 23, 647-678, (1989).

6. Chall, J., Stages of Reading Development. New York: McGraw Hill, (1983).

7. Çubukçu F., Enhancing vocabulary development and reading comprehension through metacognitive strategies. Issues in Educational Research, 18(1), 1-11, (2008).

8. Galishnikova, E.M., Monitoring model of the quality of higher education by means of a foreign language. Applied and Fundamental Studies: Proceedings of the 3rd International Academic Conference. August 30-31, 2013, St. Louis, Missouri, USA. Publishing House Science and Innovation Center, Ltd., 250-252, (2013).

9. Flavell, J. H., Metacognitive aspects of problem solving. In L. B. Resnick (Ed.), The nature of intelligence. Hillsdale, NJ: Erlbaum, (1976). 
10. Gear, J. \& Gear R., Cambridge Preparation for the TOEFL $\AA$ Test Book with CD-ROM 4th edition, (2006).

11. Gorelova, Y. N., Zalyaeva E.O., Sungatullina D.D., Examination text structure as an indicator of examination task type and complexity (on the basis of GCSE English Language Unit 1 Section A Reading). Mediterranean Journal of Social Sciences, 2015, 6, (3), 430-436, (2015).

12. Ismagilova L.,Polyakova O., The problem of the syllabus design within the competence approach based on the course "English for Master Degree Students in Economics (advanced level)", Procedia - Social and Behavioral Sciences, 152, 10951100, (2014).

13. Khusainova A., Rahmatullina A. English Language Training Volunteer Program as a New Reality for Russia and its Social Benefits. Procedia - Social and Behavioral Sciences, 152, 1101-1107, (2014).

14. Kudryavtseva M. G., Possibilities of Distance Learning as a Means of Foreign Language Learning Motivation among Students of Economics, Procedia - Social and Behavioral Sciences, 152, 1214-1218, (2014).

15. Mardanshina R., Zhuravleva E., Model of Complementary Linguistic Education for Economists, Procedia - Social and Behavioral Sciences, 152, 1091-1094, (2014).

16. Mehrdad A.G., Ahghar M.R., Ahghar M., The effect of teaching cognitive and metacognitive strategies on EFL students' reading comprehension across proficiency levels. Procedia - Social and Behavioral Sciences, 46, 3757 - 3763, (2012).

17. Mokhtari, K., \& Sheorey, R., Measuring ESL students' awareness of reading strategies. Journal of Developmental Education, 25, (3), 2-10, (2002).

18. Phakiti, A., A closer look at the relationship of cognitive and metacognitive strategy use to EFL reading achievement test performance. Language Testing, 20 (1), 26-56, (2003).

19. Zhang, L. J., Awareness in reading: EFL students metacognitive knowledge of reading strategies in an acquisition-poor environment. Language Awareness, 10, 268-288, (2001). 